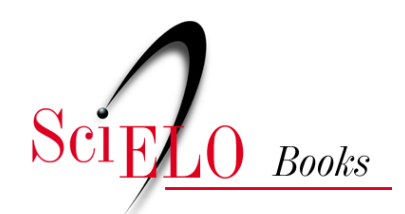

\title{
La yerba mate en el prisma de la historia ambiental, Misiones (Argentina)
}

\author{
María Cecilia Gallero
}

\section{SciELO Books / SciELO Livros / SciELO Libros}

GALLERO, M.C. La yerba mate en el prisma de la historia ambiental, Misiones (Argentina). In: GERHARDT, M., NODARI, E.S., and MORETTO, S.P., eds. História ambiental e migrações: diálogos [online]. São Leopoldo: Oikos; editora UFFS, 2017, pp. 193-214. ISBN: 978-85-64905-68-9. https://doi.org/10.7476/9788564905689.0013.

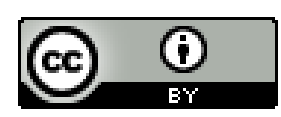

All the contents of this work, except where otherwise noted, is licensed under a Creative Commons Attribution 4.0 International license.

Todo o conteúdo deste trabalho, exceto quando houver ressalva, é publicado sob a licença Creative Commons Atribição 4.0.

Todo el contenido de esta obra, excepto donde se indique lo contrario, está bajo licencia de la licencia $\underline{\text { Creative Commons }}$ Reconocimento 4.0. 


\section{La yerba mate en el prisma de la historia ambiental, Misiones (Argentina)}

María Cecilia Gallero

\section{Introducción}

La yerba mate es una de las producciones más representativas de la economía de la Provincia de Misiones, Argentina. Por largo tiempo extraída de los yerbales naturales, fue explotada sin mayores efectos en la selva que la cobijaba hasta fines del siglo XIX. Sin embargo, esta situación cambió cuando comenzó a explotarse comercialmente, y de manera radical cuando pasó a cultivarse.

Este capítulo tiene como objetivo mostrar la transformación que sufrió el medioambiente de Misiones a partir de la implementación de los yerbales cultivados a principios del siglo XX. Para ello, se ha tomado como estudio de caso la Cooperativa de "Productores de Yerba Mate de Santo Pipó S.C.L.", pues además de ser la primera cooperativa especializada, fue fundada por suizos que migraron con el fin de dedicarse al cultivo de la yerba mate.

Estudiar la producción de la yerba mate a través del prisma de la historia ambiental permite explicar el impacto provocado por los seres humanos en el territorio misionero. En este sentido, la llegada de inmigrantes suizos tuvo especial repercusión en la mudanza de una economía extractiva a una productiva, pues contribuyeron a arraigarla como cultivo intensivo y explican la razón por la cual la Argentina sea el principal productor mundial de yerba mate, seguido por Brasil y Paraguay (INYM, 2017).

El rastreo bibliográfico sobre la yerba mate realizado merecería un extenso análisis, que aquí se presenta como una escueta síntesis por razones de extensión. Al respecto, es necesario aclarar que a principios del siglo XX la producción historiográfica se remite a los aspectos productivos de la yerba y a sus formas de industrialización (GALLARDO, 1898; GALARZA, 1914; ASTRADA, 1925; GIROLA, 1923), para pasar a los problemas que generó su producción (DAUMAS, 1930; FURNUS, 1930; BUNGE, 1936; MACKINNON \& COELHO, 1932; MUELLO, 1929 y PASTORE, 1936), 
o analizarla desde su economía (BILLARD, 1944; FREAZA, 2002). De hecho, la tesis doctoral de Alfredo Bolsi (1986) es una investigación pionera en la Argentina para la historia ambiental yerbatera, pues estudia la relación de la yerba mate con el poblamiento de Misiones, desde sus fases extractiva y productiva; y la reciente tesis doctoral sobre História ambiental da ervamate (2013) de Marcos Gerhardt evidencia el interés que genera la pesquisa sobre los cambios socioambientales en la extracción, comercio y consumo de la yerba en Brasil.

Los trabajos de Angélica Amable y Liliana Rojas (1989), Raúl Martínez Crovetto (1995), Alejandro Larguia (2006), Javier Gortari (2007), Gerónimo Lagier (2008) y Pau Navajas (2013) tratan distintos aspectos sobre la historia de la yerba mate, en tanto que la tesis de Víctor Rau (2012) se enfoca en su cosecha y los modos de producción y Daniel Slutsky (2014) analiza el complejo yerbatero en el nordeste de la Argentina. Ténganse en cuenta que el área actual de producción nacional abarca Misiones y el nordeste de Corrientes.

En el mundo, la yerba mate desempeña un papel muy importante en el contexto cultural, histórico y económico de la región misionera. Se trata de una planta cuya composición química posee diversos compuestos de interés y, además de los usos tradicionalmente conocidos, se están desarrollando nuevos productos, como energéticos, suplementos alimenticios, remedios, cosméticos y productos de limpieza. El modo más usual de beberse es como mate (infusión caliente), tereré (infusión fría) o mate cocido (en saquitos de té).

La creciente demanda de yerba mate en los mercados de América del Norte, Europa y Asia dan como resultado el crecimiento vertiginoso de las investigaciones científicas sobre esta especie, que pueden apreciarse en el congreso Sul-americano da erva mate, a nivel internacional que se inició en Curitiba en el año 1997 y ha tenido la séptima edición en Erechim en el 2017. ${ }^{1}$

El eje vertebral de este capítulo ha sido organizado en tres partes: una primera da cuenta de los antecedentes de la yerba, haciendo énfasis en las características de la economía extractiva; una segunda analiza y describe la

\footnotetext{
${ }^{1}$ Luego de más de veinticuatro años de encuentros, se formalizó el Convenio de Cooperación entre los institutos de los tres países productores: IBRAMATE de Brasil, INYM de Argentina, y el Centro Yerbatero Paraguayo <http://www.jornalboavista.com.br/site/print/28704>. Acceso en: 09 maio 2017.
} 
llegada de profesionales que inician la producción del "oro verde" a gran escala, y en la última se exploran los cambios generados por la implantación de los yerbales cultivados.

\section{Algunos antecedentes de la yerba mate, de la economía extractiva y otras yerbas}

La yerba mate, Ilex paraguariensis St. Hilarie ${ }^{2}$, debe su nombre a la descripción que hizo el explorador francés Augustin Saint-Hilaire, quien entre 1816 y 1822 recorrió Brasil y Paraguay estudiando y describiendo plantas y animales, muchas de ellas de la Selva Paranaense que se extendía en gran parte de la antigua "Provincia Jesuítica del Paraguay" (MAEDER, 2013), de allí el apelativo de paraguariensis.

Esta característica le otorga a la yerba mate no sólo una ubicación especial en el globo terráqueo, sino además, un margen de estudio que se ve acotado a los límites geográficos propios de su especie, pues la yerba es un ejemplar natural del soto bosque de la Selva Paranaense, la cual también es conocida como Bosque Atlántico del Alto Paraná o Mata Atlántica Interior ${ }^{3}$. Investigaciones como las de Dean Warren (1996), Mundstock Xavier de Carvalho (2010) o Diogo de Carvalho Cabral (2014) dan cuenta de las transformaciones que ha sufrido la Mata Atlántica, mientras que la compilación realizada por Ibsen de Gusmão Câmara (2005) analiza la situación de la biodiversidad y sus perspectivas de conservación.

Un breve recorrido sobre la yerba mate da cuenta que la población Guaraní la utilizaba otorgándole un rol social y un rol de intercambio, especialmente para el trueque con otros pueblos prehispánicos, como los Incas, Charrúas o Araucanos; siendo la misma recolectada exclusivamente de las plantas nativas existentes en la selva.

A los pocos años de iniciada la conquista, la yerba pasó a ser un producto codiciado, tal es así, que los españoles de la ciudad de Asunción

\footnotetext{
${ }^{2}$ La yerba mate, cuyo nombre vernáculo además del mismo es caá o ka'a (planta) en Paraguay y erva-mate o congonha en Brasil. Es descripta como un árbol perenne de 8 a 20 metros de altura y 0.20 a 1.50 metros de diámetro, con una copa redondeada y follaje denso de color verde oscuro (SPICHIGER, 1989, p. 44).

${ }^{3}$ E1 Bosque Atlántico o Mata Atlántica del Alto Paraná es la ecorregión más grande (471.204 $\mathrm{km}^{2}$ ) que se extiende desde los faldeos occidentales de la Serra do Mar, en Brasil, hasta el este de Paraguay y la provincia de Misiones, en la Argentina (DI BITETTI; PLACCI; DIETZ, 2003).
} 
desde temprano pretendieron tener la exclusividad del negocio, pidiendo al Rey que "las islas y montes que hay en la comarca que dicen de maracayu [...] conozcan ser pertenecientes a la dicha ciudad y en ellas se pueda beneficiar la dicha yerba..."4. Aunque al poco tiempo, Hernando Arias de Saavedra prohibió su comercio, los jesuítas consiguieron que la sexta Congregación Provincial del año 1637 aprobara "no sólo la producción de la yerba mate para consumo de las reducciones, sino también para la exportación" (ROULLIÓN ARRÓSPIDE, 1997, p. 224).

Fue así como la yerba se convirtió en un excelente recurso para las reducciones, pues encontraron la manera de cultivarla cerca de las mismas transformándose en un producto muy importante para la economía reduccional (RIVAROLA PAOLI, 1986; MÖRNER, 1968).

Con la expulsión de los jesuítas en 1767, sobrevino una etapa de desestructuración en la región que se vio acentuado por el proceso independentista, en el que la expansión territorial se dio en áreas no dominadas por los imperios español y portugués (LEAL, 2013, p. 51). La evolución yerbatera que nos ocupa, forma parte de un proceso más amplio en el cual los países vecinos, Brasil y Paraguay desempeñaron papeles de importancia al explotar comercialmente la yerba mate. Alfredo Bolsi lo sintetiza así: mientras Brasil se vio favorecido por la enorme extensión de los yerbales paranaenses que abarcaban buena parte de sus planaltos y se constituyeron en una sólida base para alimentar sus pretensiones comerciales; Paraguay, se convirtió en el gran exportador sudamericano de yerba mate haciendo uso de los amplios manchones de yerba natural que poseía (BOLSI, 1986, p. 37).

Las tierras misioneras que habían sido disputadas por Paraguay y la provincia de Corrientes, tuvieron sus límites definidos con dicho país luego de la Guerra de la Triple Alianza (1865-1870), y con Brasil después del Laudo Cleveland (1895).

En el territorio misionero, hasta entonces y aún por muchos años, la yerba provenía de las plantas silvestres que crecían en manchones con gran densidad de árboles en la selva, llamadas islas. E1 Reglamento para la Explotación de los Yerbales Fiscales, cuidadosamente elaborado y publicado

\footnotetext{
4 "Peticiones de los procuradores de la Asunción para que se ponga estanco a la yerba", Asunción 7 de noviembre de 1602. Documento 3428, Biblioteca Nacional, Colección Gaspar García Viñas, Buenos Aires.
} 
en 1876, evidencia el temprano agotamiento de los yerbales naturales (BOLSI, 1986, p. 53). Una de las principales consecuencias de su aplicación tuvo relación con el poblamiento, pues prohibía expresamente el establecimiento de asentamientos permanentes en el área de yerba mate silvestre (SAGASTIZÁBAL, 1984, p. 21-26).

Aunque no existen registros de yerbales que hayan sido cultivados en el siglo XIX, el naturalista Amado Bonpland recibió una concesión para poner en marcha en Santa Ana una empresa yerbatera ${ }^{5}$ (ARECES, 2010, p. 162). Aunque este intento terminó en cautiverio, Bonpland describe que el yerbal de Candelaria era el único implantado en tiempo de los jesuítas que podía ser explotado comercialmente, pero no lo cosechaban por temor a los paraguayos (MACHON, 2004, p. 23).

Las riquezas naturales de la selva misionera serían explotadas por Corrientes, como lo evidencia la creación de la "Jefatura Militar en Misiones para la Policía y protección de yerbales” (1856), institución que sentó las bases de la actual Policía de la provincia.

Poco antes de la creación del Territorio Nacional de Misiones (1881), el Ministro de Gobierno correntino, Manuel Mantilla, en un intento vano por mantener el control sobre este territorio, presentó una Memoria a la Honorable Cámara Legislativa de la Provincia que informaba los datos necesarios para "ilustrar la cuestión referente a Misiones". En dicho documento había un apartado dedicado especialmente a los yerbales situados en las "Altas Misiones, extendiéndose sobre una inmensa zona del territorio transitable solamente por estrechas picadas, parajes muy distantes de los centros de población más avanzados" (MANTILLA, 1879, p. XCV). Con la federalización de Misiones, el Estado Nacional se encontró con que la tierra había pasado a manos privadas en su gran mayoría. Sin embargo, la legislación establecida en Corrientes continuó vigente, permitiendo la explotación económica de los yerbales a través de concesiones. En las tierras particulares comenzaron a surgir obrajes que tenían como principal interés beneficiarse de la extracción de "maderas de ley", las que a medida que se volvían escasas, cobraban interés otras menos valiosas pero más abundantes,

\footnotetext{
${ }^{5}$ Amié Jacques Bonpland (n. 1773 en La Rochelle Francia), conocido como Amado Bonpland estuvo cautivo del Dictador José Gaspar Rodríguez de Francia entre 1821-1831, período en el cual ejerció su profesión como médico y se ocupó de la agricultura y ganadería. Luego se instaló en Santa Ana, actual Bonpland en la provincia de Corrientes, lugar en el que residió hasta su fallecimiento el 11/05/1858.
} 
y así de modo sucesivo, se fueron reiterando los ciclos de extracción depredadora, sin que hubiese una adecuada reposición natural de las especies extraídas (GARCÍA FERNÁNDEZ, 2002, p. 28).

La extracción de la yerba se realizaba en comitivas, tal como lo había descrito Ruiz de Montoya muchos años antes: "Tiene la labor de aquesta yerba consumido muchos millares de indios; testigo soy de haber visto por aquellos montes osarios bien grandes de indios, que lastima la vista el verlos..." (RUIZ DE MONTOYA, [1639] 1989, p. 63). El trabajo excesivo que suponía para los indígenas buscarla; faenarla y trasladarla había sido una de las principales oposiciones de los jesuítas al laboreo de la yerba. Una realidad que se reiteró en la figura del mensú, la que atraviesa el imaginario local (GALLERO, 2013), y reflejó la dura realidad laboral de los trabajadores de la yerba mate natural en un medio selvático como la Mata Atlántica, situación que se reitera en los cablocos cosecheros de yerba mate en Brasil, como bien retrata Gerhardt (2009, 2011 y 2013). En Argentina este período se inicia aproximadamente en 1875 con la explotación de yerbatales situados en la selva del actual territorio de Misiones, y finaliza en 1930, cuando se prohíbe por ley la extracción de yerba mate de los bosques naturales, ya completamente sustituida por la producción bajo cultivo (RAU, 2012, p. 40).

Para finalizar este apartado, se muestra la división de los yerbales naturales en la concesión realizada en el año $1904 .^{6}$ En el mismo se encuentran los respectivos permisos y resoluciones que habían sido otorgados a propietarios particulares para la explotación de los yerbales. Es interesante ver uno de los mapas que se adjunta al pedido de los solicitantes (Imagen 1), en el cual se ubican los campamentos de los interesados, como ser E. Deagustini y Cía., Antonio Alvez, Carlos Bosetti, Arturo Escalada, Nuñez y Gibaja. De la imagen se desprende que las picadas abiertas eran transitadas hacia los campamentos, y, que además, los yerbales no estaban formados como manchones uniformes, sino que se encontraban mezclados con otros árboles del monte, lo que dificultaba su localización.

\footnotetext{
${ }^{6}$ Los yerbales fueron divididos en cuatro secciones: 1) Yerbales viejos, situados al oeste del arroyo Acaraguay o Barra Bonita; 2) Yerbales nuevos, los comprendidos entre ese último arroyo y la picada de Fracrán o Paggi sobre el río Uruguay; 3) Yerbales de San Pedro, situados entre la picada mencionada y el límite con Brasil; y 4) Yerbales de San Antonio, los situados en la región limitada por los arroyos San Antonio y Uruguaí, y los ríos Iguazú y Paraná. Este documento fue gentilmente cedido por Miguel Angel Stefañuk.
} 
Imagen 1: Plano de Campamentos de yerba del $3^{\circ}$ Grupo en San Pedro (1904)

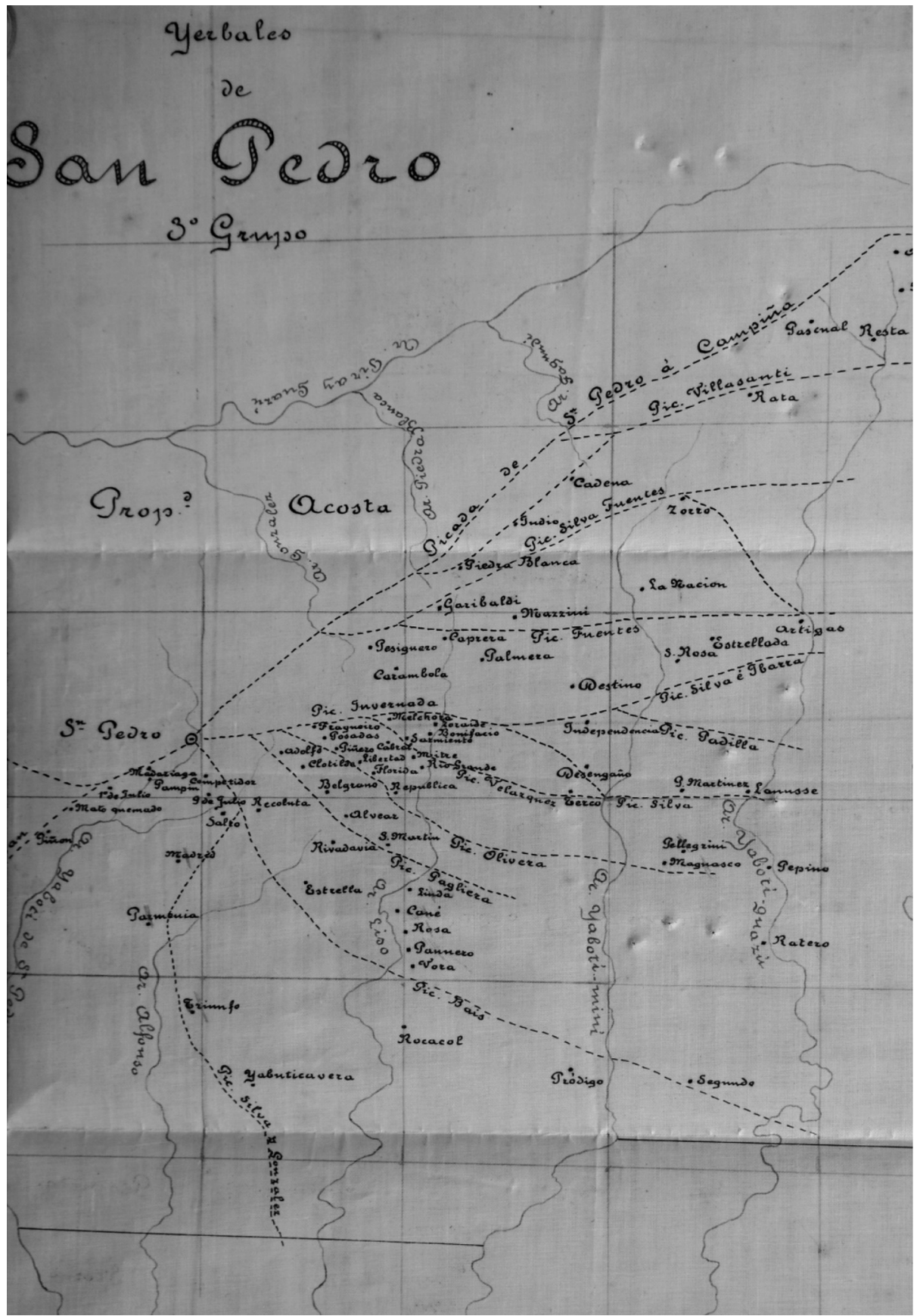

Fonte: Gentileza de Miguel Ángel Stefañuk 
El control del gobierno, aunque intentaba mantener el recurso, no llegaba a proteger la capacidad de autorecuperación de los yerbales. Carlos Gallardo presentó un informe que fue publicado con el objeto de "divulgar el conocimiento del estado en que se encuentra la industria yerbatera y las causas que obstaculizan su desenvolvimiento" (1898, p. 1). El declive producido por la expoliación de los yerbales coincidió con los albores de su cultivo, como se verá en el siguiente apartado.

\section{Conocimientos aplicados a la producción del "Oro Verde"}

A principios del siglo XX, mientras los yerbales naturales agonizaban y la economía extractiva empezaba a tener fin, la implantación de yerbales cultivados posibilitó la colonización del territorio, y todavía hoy, sigue movilizando su economía. En este sentido, la Colonia de Santo Pipó es paradigmática para estudiarla bajo el prisma de la historia ambiental, pues ayuda a comprender por qué los yerbales impregnan su paisaje.

La estructura socioeconómica del nuevo Territorio Nacional plantaciones, empresas agroindustriales, etc. - se constituyó principalmente sobre la base de la iniciativa privada. La yerba mate necesitó de un cuidadoso trabajo de investigación para poder cultivarse. Aunque la idea de que este secreto se había ido con la expulsión de los jesuítas estaba muy difundido, Johann Rengger, un viajero suizo y farmacéutico de profesión, que compartió parte de la travesía y cautiverio con Amado Bonpland ${ }^{7}$, describió el proceso de cultivo de la yerba en 1826. La descripción que realiza Rengger evidencia cómo la yerba se sigue reproduciendo en el presente, con los cuidados y estudios genéticos que esto implica (SCHERER, 2001; SCHMALCO et al., 2015). A fines del siglo XX, Carlos Thays había redescubierto la forma de hacer germinar la semilla, con la diferencia que la trató con agua caliente. Una observación que se debe remarcar, es que la yerba, como especie del sotobosque, es muy delicada en relación al suelo, con preferencias de las

\footnotetext{
${ }^{7}$ Johann Rudolf Rengger (n. Baden, Suiza 13 jan. 1795) estudió Ciencias Naturales y Farmacología en Suiza y Alemania. En 1817 obtuvo el grado de Doctor en Farmacología por la Universidad de Tübingen. Un año después, junto con su colega Marcel Longchamp, viajó a Sudamérica donde ambos habrían de ejercer la medicina y efectuar estudios científicos. En julio de 1818 arribaron al puerto de Buenos Aires, donde conocieron a Amado Bonpland. E1 Paraguay, estuvo retenido por el dictador José Gaspar Rodríguez de Francia, hasta que en 186 se le permitió viajar a Buenos Aires. Rengger falleció en Aarau, Suiza, en 9 out. 1832.
} 
formaciones a partir de basalto, denominados latosoles, medianamente profundos a profundos - conocidos como suelos "rojos" -, además de ser una planta muy susceptible al frío y al calor, y con extrema sensibilidad a la exposición solar. Esto hace que plantación definitiva en el campo requieriese de cuidados especiales, tales como "ponchos" o "pantallas" (Imagen 2) que protegieran a los tiernos plantines de yerba mate (SPRECHER von BERNEGG, 1936).

Imagen 2: Diferentes protectores o pantallas para los plantines de yerba recién trasplantados

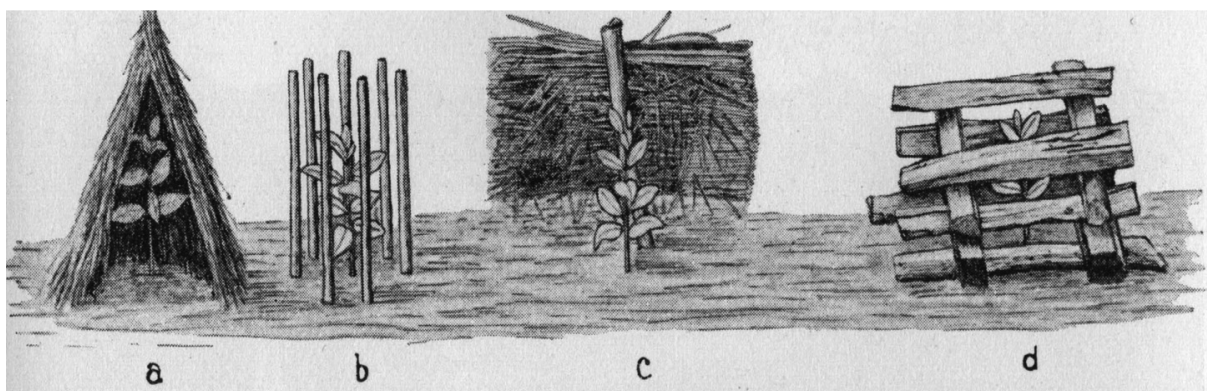

Fig. 17. Beschattung der jungen Pflanzen mit ponchos (a) oder estacas (b) oder pantallas (c) oder aripucas (d).

Fonte: Sprecher von Bernegg, 1936, p. 339

En San Ignacio se encuentran los antecedentes de los yerbales de cultivo. A Julio U. Martin, fundador de la firma Martin y Cía., "le cabe el honor de haber sido el primer plantador en escala comercial" (NUÑEZ, 1997, p. 116). Martin era un inmigrante suizo francés proveniente del cantón de Vaud, que luego de arribar a la Argentina se estableció en Paraguay en 1885. Mientras estaba allí, el presidente Roca le escribió 1: "Usted, señor Martin, se propone hacer en el Paraguay lo que nosotros necesitamos hacer aquí. [...] plante yerba mate en nuestro país y haga sus plantaciones en nuestras colonias de Misiones" (MARTIN, 2004, p. 48). Fue así como a fines de 1902, Martin vino a Posadas para reunirse con el gobernador Juan José Lanusse, quien le recomendó que se asociara con su yerno Pablo Allain, un suizo ingeniero agrónomo diplomado en la Universidad de Montpellier -Francia- que experimentaba con la implantación de yerbales en San Ignacio. 
Pronto otros suizos se sumaron al nuevo emprendimiento. Como Ernesto Addor, quien también era originario del cantón de Vaud y llegó a San Ignacio del Paraguay para administrar el secadero de yerba de Martin y Cía. El conocimiento del negocio de la yerba atrajo a Eugenio Lagier, un suizo francés que se instaló en Candelaria y desde allí proyectó con su vecino Luciano Leiva - un acaudalado ganadero santafecino - la colonia de Santo Pipó (GENTILUOMO DE LAGIER, 2008). Para ese entonces, Santo Pipó era un obraje destinado a la extracción de maderas de ley, con una población obrera de unos 130 hombres, en tanto que San Ignacio se destacaba por las "yerbas de cultivo", tal como había informado José Elías Niklison en 1914. Esta transición entre los yerbales naturales y los de cultivo fue retratada por Francisco Foulliand en Historia de la industria yerbatera en Misiones (1915).

Asimismo, es necesario puntualizar que Eugenio Lagier se vinculó con el gobierno suizo para organizar la colonización e interesar a sus compatriotas en la implantación de yerbales. Especialmente se puso en contacto con los futuros agrónomos de la Escuela Politécnica Federal de Zürich (Eidgenössische Technische Hochschule - ETH), en la cual el profesor Andreas Sprecher von Bernegg - especialista en la investigación de plantas tropicales - describió con entusiasmo la Ilex paraguariensis y aconsejaba a sus estudiantes no ir solamente a Java a plantar cauchera o al África palmeras de aceite, sino de ir a la Argentina a plantar yerba mate en Misiones (SPRECHER von BERNEGG, 1936, ZIMAN; SCHERER, 1976, p. 167).

La colonia de Santo Pipó fue fraccionada en lotes de 100 hectáreas, lo que evidencia que se planificaron propiedades de tamaño mediano-grande, sobre todo si se tiene en cuenta que en ese entonces el promedio de una chacra en otras colonizaciones era de 25 hectáreas. En este proceso la política se convirtió en un factor de primer orden, como lo evidenció el decreto de 1926, que obligó a los concesionarios de las colonias estatales a plantar y cultivar yerba mate en una fracción de la superficie concedida (BOLSI, 1986, p. 117).

Estos jóvenes ingenieros agrónomos e inmigrantes, desde ahora "yerbateros", vinieron dispuestos a lograr plantaciones modelo a gran escala. Fueron denominados "inmigrantes suizos de élite" (GLATZ, 1997, p. 165), pues en su mayoría eran de origen urbanos, poseían capital propio para invertir. En algunos casos actuaron como representantes de firmas suizas que realizaban inversiones, como fue el caso de Víctor Schöpfer que representaba a Lecoultre y Cía. - una importante fábrica de relojes -; en otros 
representaban a amigos o familiares integrantes de bancos suizos que enviaban capitales. Esta característica le dio un tinte particular a Santo Pipó, pues eran profesionales que consiguieron el respaldo de capitales para emprender su sueño de ser "plantadores de yerba mate" o "hierbateros", como se autodenominaron algunos al llegar al puerto de Buenos Aires (GALLERO, 2011, p. 24-25).

Para los europeos fue la "maravilla de la yerba mate, porque se plantaba una vez y se podía cosechar todos los años la misma planta" (ORUETA DE BUZER, entrevista, 2010). Aunque las plantaciones al principio sufrieron reveses, causadas por la sequía o invasión de langostas, entraron a dar sus frutos entre los cuatro y cinco años de haberse iniciado. Esta producción había que sapecar y secar, para lo cual la idea cooperativa ayudaba a afrontar los gastos que implicaba un secadero. François Machon analizaba, casi contemporáneamente, que seguramente los colonos de Santo Pipó establecieron "bajo la forma cooperativa, fábricas centrales a donde irán con su yerba sapecada, como en casa los campesinos van al lugar comunal a separar los granos de trigo" (MACHON, F. 1927).

La Cooperativa "Productores de Yerba Mate de Santo Pipó" (en adelante PYM) tuvo sus comienzos como una sociedad que tenía el objetivo de organizar de manera conjunta la secanza de la yerba producida por los asociados, la que se vio formalizada en una "Asamblea General de Socios del Secadero" el 27 de junio de 1933.

Desde sus inicios, sus fundadores aplicaron conocimientos técnicos, como lo demuestra la implementación de la sapecadora mecánica y un secadero tipo catre (que luego evolucionó al secadero a cinta), ambas invenciones de uno de sus socios: Esteban Roulet. Estas invenciones impactaron a largo plazo, puesto que a partir de este momento la estructura productiva de la provincia iniciara el procesamiento de la producción primaria.

La incipiente producción de yerba mate se tropezó con la competencia brasileña como un primer obstáculo, pues Argentina era un gran mercado demandante de yerba mate que se satisfacía prácticamente a través de la importación. La economía del estado de Paraná se encontraba dominada por la producción de yerba mate con destino a nuestro país (BARSKY; GELMAN, 2001, p. 249; MAGAN, 2004).

Por otra parte, la década de 1930 vino acompañada por un cambio en la producción yerbatera. De ser fuertemente incentivada y propiciada por 
el Estado, pasó a ser regulada. Esto se debió a que el aumento de la producción del cultivo en la Argentina comenzó a amenazar con desplazar por completo a la brasileña de su principal mercado. A esto se sumó, que existía un sector de la producción y comercialización representado por los molineros que tenían interés en que continuase ingresando la yerba canchada brasileña, pues constituía su materia prima y les convenía mucho por su bajo precio.

De modo que el destino de la yerba comenzó a estar ligado al del trigo, puesto que, si Brasil adquiría nuestro trigo, Argentina debía seguir comprando yerba brasileña. La gravedad de esta situación estaba dada por la importancia que la exportación de este artículo tenía para el Estado de Paraná, que en el período 1926-1927 había representado casi un 24\% del total recaudado por el fisco estadual, siendo el mayor ingreso producido por cualquier ítem en sus rentas. De aquí se desprende que la necesidad de regular la producción de yerba mate argentina fue para dar cabida a la producción brasileña (MAGAN, 2004).

Este fue el comienzo de la actuación de la Comisión Reguladora de la Yerba Mate (CRYM), creada en el año 1935, con el objetivo de evitar que la yerba argentina no se expandiera más allá de las plantaciones existentes. Se estableció un impuesto por cada planta nueva que se radicara y organizó el Mercado Consignatario de la Yerba Nacional Canchada (ZARRILLI, 2007, p. 103). Esta Comisión, que había sido creada para defender al sector económico en crisis, también contribuyó a consolidar el monopolio productivo y comercial, en el que unos pocos molinos controlarían el mercado yerbatero.

Desde ese momento, una de las palabras claves pasó a ser "cupo". La CRYM otorgaba cupos para plantación, cupos de cosecha, se transfería el cupo de un yerbal viejo para reemplazar por uno nuevo, se vendían los cupos pero no el yerbal ni la tierra y en la economía regulada todo giraba en torno al cupo (LAGIER, 2008, p. 147). Con este sistema regulado y con la aceptación de nuevos socios, se constituyó la base productiva de la PYM que funcionó de forma estable secando la yerba de sus asociados.

La provincialización de Misiones (1953) fue testigo de un cambio que marcó un giro en la historia de la PYM: fue la decisión de moler yerba y comercializarla bajo la marca "Piporé". Para poder concretar la industrialización y comercialización de su propia yerba se construyó un molino de 12.000 kilos de capacidad en 8 horas - suficiente para absorber la 
producción de los secaderos -, un pequeño edificio administrativo, la ampliación de galpones, elevando la capacidad de almacenaje a cerca de 1.000.000 de kilos, y la construcción de 14 casas para obreros y empleados.

Con la provincialización de Misiones (1953) se logró trasladar la CRYM a la zona productora e impulsar el desarrollo de los molinos locales. Hasta el año 1991 la actividad yerbatera estuvo regulada, año en que se inició un período de libre competencia, caracterizado por la abundancia de la materia prima y la caída paulatina de los precios al productor (FREAZA, 2002, p. 118). Después de 50 años de regulación estatal, la desregulación condujo a un manejo oligopólico de la comercialización, provocando una crisis social inédita que llevó a los gobiernos provincial y nacional a la creación del Instituto Nacional de la Yerba Mate (INYM) en el año 2002, cuya primera función fue mejorar el precio de la materia prima (GORTARI, 2007, p. 401-423), y actualmente su misión "es lograr una actividad yerbatera con la mayor cantidad de actores, competitiva, socialmente responsable, equitativa y ambientalmente sustentable, que ofrezca al mundo productos naturales, genuinos y de calidad" (INYM, 2017).

\section{El cultivo de la yerba mate y la transformación del ambiente}

Las huellas dejadas en el paisaje son el reflejo de las transformaciones que ha tenido el ambiente en el tiempo, por ello en este apartado se rastrea el impacto que generó la implementación de la yerba mate como monocultivo.

Como toda actividad agrícola, la primera etapa para realizar un yerbal consiste en definir el lugar adecuado donde instalarlo y proceder a la habilitación del terreno. Para ello hay que eliminar el monte o selva paranaense, proceso que se puede hacer de diferentes maneras. En general, la primera fase reside en machetear el sotobosque y extraer los árboles de mayor porte destinándolos a la industria maderera, luego voltear los árboles secundarios sin valor aserrable para producir leña junto a las copas de los primeros árboles de mayor porte.

Piénsese en la selva paranaense original como un gran manto de 40 metros de altura que estaba en el "climax" de su desarrollo, en el que flora y fauna estaban equilibrados. Esta situación de equilibrio se vio radicalmente modificada con la acción antrópica que reemplazó este medio por un monocultivo de una especie arbórea que normalmente se desarrollaba bajo 
la protección del estrato superior del bosque (vegetación umbrófila), como ser araucarias (Angustifolia), lapachos (Tebebuia heptaphylla), palo rosa (Aspidosperma polyneuron), cedro (Cederela fissilis), etc. Árboles que filtran el agua y la retienen por medio de las raíces, interceptan la radiación solar y protegen a las especies vegetales de los estratos inferiores, como ser la yerba mate.

De modo que para llegar al yerbal, se pasó por un extremo en el cual el bosque es totalmente eliminado con distintos grados de pérdida, ya sea por extracción o quema, en donde el suelo queda, según el caso, más o menos expuesto a factores ambientales del subtrópico: inicialmente con un incremento momentáneo de la materia orgánica, pero debido a la falta de nuevos aportes y la alta de tasa de mineralización rápidamente pierde la materia orgánica mientras se va estableciendo el cultivo, que requiere protección contra el sol, el frío, intensas lluvias, plagas y enfermedades.

Un paso importante era obtener buenas plantas de yerba en el vivero. Las plagas específicas de la yerba mate y algunas oportunistas se concentran en el único material disponible que son las jóvenes plantitas, haciendo más difícil el desarrollo pleno del yerbal. Transcurridos los años, la plantación se convierte en un nuevo tapiz vegetal de escasos metros de altura y en el que se va alcanzando un nuevo equilibrio más o menos estable de acuerdo al manejo y a los cuidados culturales que se extendieron a lo largo de la vida del yerbal, que consisten en cubiertas verdes, control de malezas, devolución de nutrientes exportados con la incorporación de materia orgánica y/o fertilizantes (SCHMALKO et al., 2015).

La erosión del suelo fue uno de los primeros impactos que se estudiaron en el proceso al establecer un yerbal. Alberto Roth realizó prematuras observaciones sobre este problema en Santo Pipó, pues se percató de la fragilidad de los suelos misioneros (ROTH, 1940 y GALLERO, 2014). Estaba claro que al eliminarse la vegetación nativa y trabajarse la superficie de la tierra comenzó uno de los problemas más serios que fue considerado entre las primeras leyes de la Provincia, Ley n. 9 Conservación del suelo agrícola ${ }^{8}$.

Desde que se plantaron los primeros yerbales en Santo Pipó han pasado muchos años, las primeras plantaciones se registraron en el año 1924. En las 4.000 hectáreas de yerbales que poseen los socios de la PYM,

${ }^{8}$ Ley n. 9, Conservación del suelo agrícola. Promulgada el 6 set. 1955. 
se registran yerbales de diferentes tamaños que van de media hectárea a bloques que se interconectaron a lo largo del tiempo y de diferentes propietarios en áreas de veinte a doscientas hectáreas. En esta gran variedad de cuadros, la decadencia de los yerbales implantados con anterioridad a la década de 1970 puede atribuirse a una serie de factores concurrentes, entre los que se destaca el manejo del suelo, cosechas inadecuadas en el tiempo y forma, podas incorrectas, enfermedades, plagas y adversidades climáticas. De modo que desde que los yerbales cultivados prosperaron se produjeron cambios más o menos notorios, variando densidades, marcos de plantación, cubiertas verdes, genética de las plantas, entre otras cuestiones técnicas.

La tarea artesanal de la cosecha de yerba mate no se ha podido suplantar a través de los años. Los tareferos cumplen la función de despojar gajo por gajo a la planta de yerba mate, un trabajo meticuloso para no dañar a la planta. Al principio hubo algunos casos de cosecha con escalera en plantas de yerba de gran altura (Imagen 3), pero rápidamente se pasó a formar plantas de menor altura que pueden ser cosechadas desde el suelo (Imagen 4). El profesor Sprecher von Bernegg dio pautas claras de cómo formar el árbol de yerba correctamente para asegurar su supervivencia y mantener el yerbal por varios años (1936, p. 360-366), pautas que fueron realizadas con el intercambio de sus alumnos que estaban llevando a la práctica la realización de los yerbales. Fue así como la yerba se convirtió en un cultivo en Misiones, en los cuales varía la densidad de plantación, pero se mantiene una altura que no sobrepasa los cuatro metros. En tanto que en Brasil, la preferencia por la yerba natural, propició el cultivo de yerbales de mayor altura, entre seis a ocho metros, y que actualmente se la vea como "el principal producto no maderero del país de los agronegocios forestales en la región" (VANDERLEY et al., 2016). 
Imagen 3: Cosecha de yerba con escalera en Santo Pipo, c. 1930

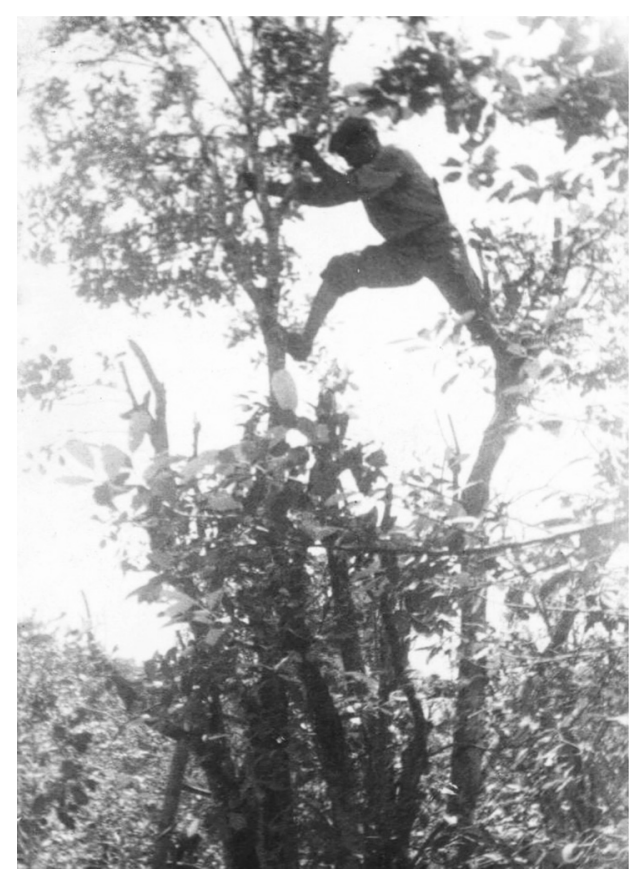

Fonte: Gentileza Elisabeth Wuergler

Imagen 4: Cosecha de yerba en Santo Pipo, c. 1920

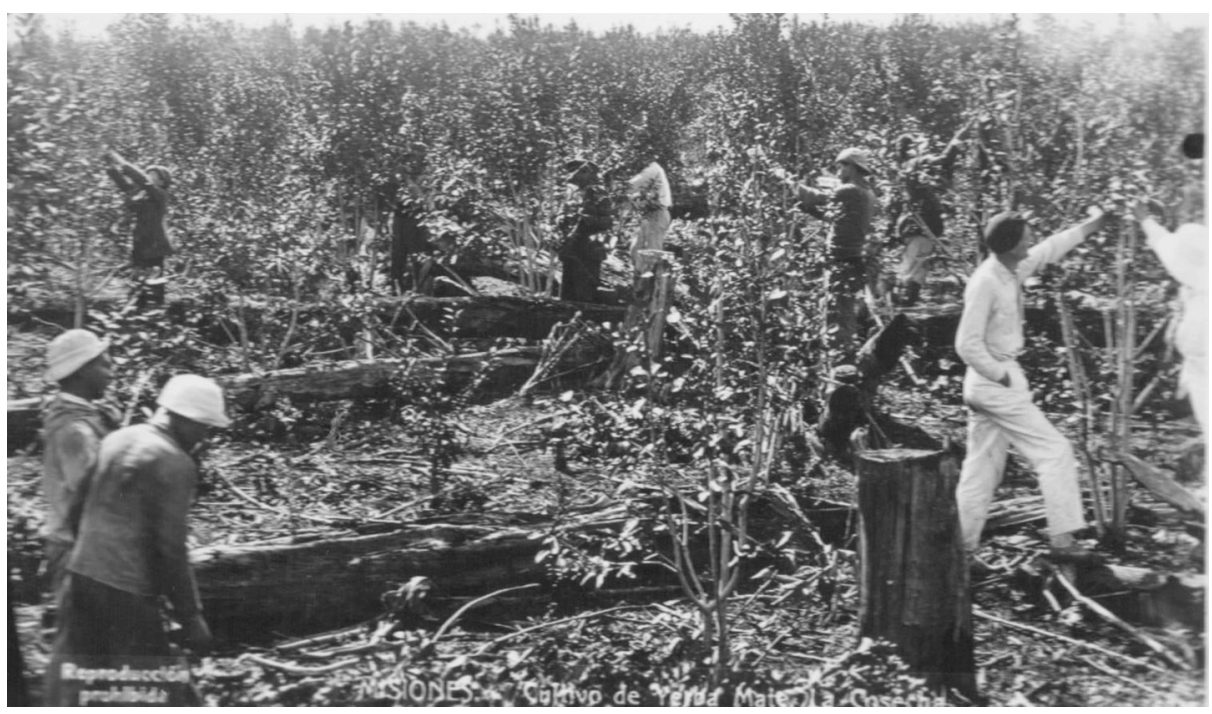

Fonte: Foto de Gastón Bourquin. Gentileza de Martha de Haller de De Coulon 
El sistema de cosecha conocido como "tradicional" sigue siendo practicado por la mayoría de los socios de la PYM. Sin embargo, luego de algunos intentos de cosecha mecanizada entre los años 1990-1991, varios socios han implementado la cosecha semimecanizada. La misma consiste en la división y especialización de las tareas, formando grupos e incorporando diversas herramientas que agilizan y ayudan al proceso de cosecha (DE COULON, 2001). Desde el corte hasta la descarga de la yerba se reduce el tiempo que demanda cada tarea, como ser el corte, quiebre, pesaje, carga y descarga de raídos.

Toda la etapa productiva mencionada la realiza individualmente cada socio, en tanto que las siguientes etapas - industrialización y comercialización - son realizadas cooperativamente. En la actualidad, la PYM cuenta con 58 socios que explotan aproximadamente unas $4.000 \mathrm{ha}$. de yerbales con diversos rendimientos (entre $1.500 \mathrm{~kg}$ y $17.000 \mathrm{~kg}$ por hectárea). Según el resumen analítico del INYM de salidas de yerba mate estampillada de molino, la PYM se encuentra posicionada en noveno lugar. Sin embargo, si a esta producción se suma a la exportación, es decir, el mercado interno y el externo, estaría posicionada en el primer lugar como cooperativa productora de yerba mate de la región.

Finalmente, hay que agregar que en Misiones, la creación del Ministerio Provincial de Ecología y Recursos Renovables (1984) hizo efectiva una política que llevó a un notable aumento de Áreas Naturales protegidas, y conllevó a la Ley de Ordenamiento Territorial, Ley n. 3631, sancionada el 30 de noviembre de 1999. A partir de este momento, las nuevas plantaciones de yerba serán más difíciles de realizar en tierras con monte nativo, pues hay que conseguir el permiso que habilite el cambio en el uso del suelo. Lo que propicia que yerbales viejos sean renovados o convertidos en forestaciones y viceversa.

\section{A modo de conclusión}

El cultivo de yerba mate no fue solo un cambio en el paisaje, sino que significó una alteración en el orden económico y social de la provincia de Misiones. Esta alteración se vio favorecida por la colonización privada que propició la llegada de inmigrantes que vinieron con la idea de ser "yerbateros". Este grupo de emprendedores, que habían estudiado juntos que en algunos casos se conocían desde su niñez -, se unieron con el objetivo 
de compartir los beneficios de trabajar en conjunto. Así fue como nació la "Cooperativa Productores de Yerba Mate de Santo Pipó", la que muchos años fue un simple secadero y que luego de afianzarse logró montar un molino. Este cambio implicó que la cooperativa diera un salto con la marca Piporé, la que pasó a ser distribuida en el país - consolidándose en la Patagonia argentina - y exportada, especialmente en Oriente Medio.

Observar la yerba mate bajo el prisma de la historia ambiental permitió dar cuenta de las transformaciones que ha sufrido su producción y el impacto que esto generó en el ambiente. De ser una planta nativa que crecía al resguardo de la selva paranaense, comenzó a ser cultivada, dando paso a una intensa actividad de desmonte para poder implantar yerbales, que según los cuidados culturales tuvieron una producción directamente proporcional a los mismos: a mayor cubiertas verdes, buenas podas, fertilización y cuidado de plagas y malezas, una mayor producción; como puede apreciarse en algunos yerbales que actualmente tienen a una producción que sobrepasa los 17 mil kilogramos por hectárea.

Los estudios sobre la yerba mate se han vuelto más especializados, se ha logrado un profundo conocimiento de sus cualidades químicas, genéticas y productivas; y se está trabajando en cómo desarrollar su cultivo con menores impactos ambientales y ecológicos, lo que plantea un constante desafío para quien emprenda una investigación sobre sus actuales prácticas agroecológicas y su historia.

\section{Entrevistas}

ORUETA de Buzer, Angélica, 6 jun. 2010, Posadas.

\section{Fuentes inéditas}

ARGENTINA. Buenos Aires. Biblioteca Nacional, Documento 3428, Colección Gaspar García Viñas.

ARGENTINA. Ministerio de Agricultura de la Nación, Tierras y Colonias, Adj / plano demostrativo lotes que deben licitarse para explotación de yerbales en Misiones. 1907. Gentileza Miguel Angel Stefañuk.

\section{Fuentes éditas}

BARRET, R. Lo que son los yerbales. Montevideo: El Arte, 1910.

MACHON, F. Le Territoire Argentin de Misiones et la Culture du Maté, Bulletin de la Société neuchateloise de Géographie, 1927. 
MANTILLA, M. F. Memoria presentada a la Honorable Cámara Legislativa de la Provincia de Corrientes, [s.d.e.], 1879.

NIKLISON, J. E. Informe del Inspector José Elías Niklison, Boletín del Departamento Nacional del Trabajo, Número 26, 30-04-1914.

RENGGER, J. R. Reise nach Paraguay in den Jahren 1818 bis 1826 [Viaje al Paraguay en los años 1818 a 1826], Aaraux: Sauerlaender, 1835 [Gentileza de Francisco Machón].

RUIZ de MONTOYA, A. Conquista Espiritual, Hecha por los Religiosos de la Compañia de Jesús en las provincias del Paraguay, Paraná y Tape, [Estudio preliminar y notas E. Maeder], Rosario, Equipo Difusor de Estudios de Historia Iberoamericana, [1639] 1989.

\section{Referências}

AMABLE, María Angélica; ROJAS, Liliana. Historia de la Yerba mate en Misiones. Posadas: Ediciones Montoya, 1989.

ARECES, N. "De la Independencia a la Guerra de la Triple Alianza". TELESCA, I. (coord.) Historia del Paraguay, Paraguay: Taurus, 2010.

ASTRADA, I. "Progresos de la industria de la yerba mate en la República Argentina”. Revista Farmacéutica, Buenos Aires, T. LXVII, 1925.

BARSKY, O.; GELMAN, J. Historia del Agro Argentino, desde la Conquista hasta fines del siglo XX, Buenos Aires: Grijalbo Mondadori, 2001.

BILLARD, J. J. "Economía de la industria yerbatera argentina”. Instituto de Economía y Legislación, 1944.

BOLSI, A. "Misiones (una aproximación geográfica al problema de la yerba mate y sus efectos en la ocupación del espacio y el poblamiento)". In: Folia História del Nordeste, Resistencia, IIGHI-CONICET-FUNDANORD, n. 7, 1986, p. 9-253.

BUNGE, A. E. "La producción argentina de yerba mate. La cercana tragedia de la yerba mate". Revista de Economía Argentina, Buenos Aires, T. XXXV - n. 222, 1936.

CARVALHO CABRAL, D. de. Na presença da floresta: Mata Atlântica e histórica colonial. Rio de Janeiro: Garamond, 2014.

CASSAGNE SERRES, A. "Yerbales argentinos: organización, explotación, administración". Revista de la Facultad de La Plata. La Plata, Serie 3, T. XVIII, 1929.

DAUMAS, E. "El problema de la yerba mate". Revista de Economía, Buenos Aires, 1930.

DE COULON, E. Innovación tecnológica y proceso de trabajo en la cosecha de yerba mate". Disertación (Maestría en Administración Estratégica de Negocios), Universidad Nacional de Misiones, Facultad de Ciencias Económicas, 2001. 
GALLERO, M. C. • La yerba mate en el prisma de la historia ambiental, Misiones (Argentina)

DI BITETTI, M.; PLACCI, G. y DIETZ, L. A biodiversity vision for the upper Paraná Atlantic Forest Ecoregion: designing a biodiversity conservation landscape and setting priorities for conservation action. Washington DC: World Wildlife Fund, 2003.

FOULLIAND, F. Historia de la Industria Yerbatera. Posadas: Imp. Alberdi, 1915.

FREAZA, M. A. Economía de Misiones: Aspectos y Actividades Relevantes, Posadas: Editorial Universitaria de Misiones, 2002.

FURNUS, A. C. La yerba mate en Misiones: el medio ambiente. s.d., 1930.

GALARZA, J. B. "La yerba mate". Boletin del Ministerio de Agricultura, Buenos Aires T. XVIII - n. 1 y 2. 1914.

GALLARDO, C. La Industria Yerbatera en Misiones. Buenos Aires: Imprenta San Jorge, 1898.

GALLERO, M. C. El llamado del Oro Verde: Memorias de Inmigrantes Suizos en Misiones, Florida: Araucaria Editora; Misiones: Consulado Suizo, 2008.

GALlerO, M. C. Piporé, 80 años haciendo historia en la yerba mate. Buenos Aires: Productores de Yerba Mate de Santo Pipó, 2011.

GALLERO, M. C. "Memorias inversas: criollos vs. colonos a través de un estudio de caso sobre el imaginario en la colonización de Misiones". In: GIORDANO, Mariana; KLAPPENBACH, Luciana Sudar; ISLER, Ronald (Comp.). Memoria e imaginario en el Nordeste Argentino. Escritura, oralidad e imagen. Rosario: Prohistoria, 2013, p. 183-216.

GALLERO, M. C. Querida Misiones, Hermosa! A través de las memorias de Alberto Roth. Buenos Aires: Araucaria Editora, 2014.

GARCÍA FERNÁNDEZ, J. "El corredor verde de Misiones". BURKART, R. y otros, La Selva Misionera. Buenos Aires: FUCEMA, 2002.

GERHARDT, M. "A produção da Erva-Mate na Perspectiva da História Ambiental". Revista Brasileira de Agroecologia, v. 4, n. 2, 2009.

GERHARDT, M. "Colonos ervateiros: História ambiental e imigração no Rio Grande do Sul". Esboços, Florianópolis, v. 18, n. 25, p. 73-95, 2011.

GERHARDT, M. História ambiental da erva-mate. Tese (Doutorado em História Cultural), Programa de Pós-Graduação em História, Centro de Filosofía e Ciências Humanas da Universidade Federal de Santa Catarina, 2013.

GENTILUOMO DE LAGIER, E. "Las cartas de Eugenio Lagier". In: GALLERO, M. C. (Comp.). El llamado del Oro verde. Florida: Araucária Editora, 2008.

GIROLA, C. "Cultivo de la yerba mate. Consumo de la yerba mate". Museo de la Sociedad Rural Argentina, Buenos Aires, n. 34, 1923.

GLATZ, M. Schweizerische Einwanderer in Misiones. Frankfurt: Peter Lang, 1997.

GORTARI, J. (Comp.). De la tierra sin mal al tractorazo, hacia una economía politica de la yerba mate. Posadas: Editorial Universitaria de Misiones, 2007. 
GUSMÃO CAMARA, Ibsen de (Ed.). Mata Atlântica: biodiversidade, ameaças e perspectivas, São Paulo: Fundação SOS Mata Atlântica; Belo Horizonte: Conservação Internacional, 2005.

LARGUIA, A. Misiones-Itapúa y los pioneros del Oro Verde. Corrientes: Moglia SRL, 2005.

LEAL, C. "Fronteiras florestais. In: LEAL, Claudia; PADUA, José Augusto; SOLURI, John. Novas histórias Ambientais da América Latina e do Caribe. Munich: Rachel Carson Center Perspectives, 2013.

LAGIER, J. La aventura de la Yerba Mate. Buenos Aires: Ed. del Autor, 2008.

MACKINNON \& COELHO. Memorial presentado al Ministerio de Relaciones Exteriores: Yerba mate. Buenos Aires: s.1., 1932.

MACHON, J. F. El viaje de Amado Bonpland a Misiones en 1821. Posadas: Creativa, 2004.

MAEDER, E. Misiones del Paraguay, Construcción jesuitica de una sociedad cristianoguarani (1610-1768). Resistencia: ConTexto Libros, 2013.

MARTIN y Cía. Julio U. Martin y una empresa de tres siglos. Rosario: Mimeo, 2004.

MARTINEZ CROVETTO, R. La yerba mate. Buenos Aires: Museo de Motivos Argentinos José Hernández, 1995.

MÖRNER, M. Actividades Politicas y Económicas de los Jesuitas en el Río de la Plata, Buenos Aires: Paidós, 1968.

MUELLO, C. "Apuntes sobre el cultivo de la yerba mate en la República Argentina". Revista del Centro Estudiantes de Agronomía y Veterinaria Universidad de Buenos Aires. Buenos Aires: Imprenta de la Universidad, n. 138, 1929.

MUNDSTOCK XAVIER de CARVALHO, M. Uma grande empresa em meio à Floresta: A história da devastação da floresta com araucária e a Southern Brazil Lumber and Colonization (1870-1970). Tese (Doutorado em História), Florianópolis, Universidade Federal de Santa Catarina, Centro de Filosofía e Ciencias Humanas, Programa de Pós-Graduação em História, 2010.

NAVAJAS, P. y MAC DONNEL, M. Caá Porá: el espíritu de la yerba mate, una historia del Plata. Corrientes: Establecimiento Las Marías, 2013.

NUÑEZ, J. Iviraretá, país de árboles. Posadas: Ediciones Montoya, 1997.

PASTORE, D. "El oro verde". Revista de Economía Argentina. Buenos Aires, 1936, T. XXV, n. 146.

RAU, V. Cosechando yerba mate. Estructuras sociales de un mercado laboral agrario en el Nordeste Argentino. Buenos Aires: Ciccus ediciones, 2012.

RIVAROLA PAOLI, J. B. La economía Colonial. Asunción: Editora Licolor, 1986. ROTH, A. "Misiones-Probleme", Deutscher Alto Paraná Kalender, 1940, p. 71-81. 
ROULLIÓN ARRÓSPIDE, J. Antonio Ruiz de Montoya y las Reducciones del Paraguay, Asunción: CEPAG, 1997.

SAGASTIZÁBAL, L. de. La yerba mate y Misiones. Buenos Aires: Centro Editor de América Latina, 1984.

SCHERER, R. Mass and Nursery selection of Yerba Mate (Ilex paraguariensis) for Quality improvement in Argentina. Inaugural-Dissertation. University of Bonn. Cuvillier Verlag: Göttingen, 2001.

SCHMALKO, M.; PRAT KRIKUM, S.; KÄNZI, R. La Yerba Mate. Tecnología de la Producción y propiedades. Posadas: Editorial Universitaria, 2015.

SLUTZKY, D. Estructura Social Agraria y Agroindustrial del Nordeste de la Argentina. Posadas: Editorial Universitaria, 2014.

SPICHIGER, R. Flora del Paraguay. St. Louis, Conservatorie et Jardin Botaniques, Ville de Genève Missouri Botanical Garden, 1989.

SPRECHER von BERNEGG, A. Tropische und subtropische Weltwirtschaftsplanzen, ihre Geschichte, Kultur und volkswirtschaftliche Bedeutung. Stuttgart: Verlag von F. Enke, 1936.

WARREN, D. A ferro e fogo: a história e a desvastação da Mata Atlântica brasileira. São Paulo: Companhia das Letras, 1996.

ZARRILLI, A. "Quebracho y yerba mate. La producción regional del NEA frente a la crisis (1920-1940)". GIRBAL BLACHA, N.; OSPITAL, M.; ZARRILLI, A. (Eds.). Las miradas diversas del pasado. Las economías agrarias del interior ante la crisis de 1930. Buenos Aires: Ed. Nacional, 2007.

ZIMAN, L.; SCHERER, A. La selva vencida. Buenos Aires: Marymar, 1976.

\section{Internet}

INSTITUTO NACIONAL DE LA YERBA MATE (INYM). Convenio histórico entre la carne, el vino y la yerba mate argentina. 2011. Disponible en: <http:// www.inym.org.ar/2017/04/25/convenio-historico-entre-la-carne-el-vino-y-layerba-mate-argentina/>. Acceso en: abr. 2017.

INSTITUTO NACIONAL DE LA YERBA MATE (INYM). Misión. 2017. Disponible en: <http://www.inym.org.ar> Acceso en: mayo 2017.

MAGAN, Victoria. El intercambio de yerba mate entre Brasil y Argentina y los tratados de comercio de 1933 y 1935. 2004. Disponible en: <http://www.fee.tche.br/sitefee/ download/jornadas/2/h10-04.pdf>. Acceso en: mayo 2017.

VANDERLEY, Porfirio da Silva et al. Seminário Erva-mate XXI: Modernização no cultivo e diversficação do uso da erva mate. [recurso electrônico]. Curitiba, Colombo: Embrapa Florestas, 2016. 